\title{
Calculating and estimating construction site plan preparation works and temporary objects, using virtual reality technology
}

\author{
Robertas Kontrimovičius $^{1}$, Leonas Ustinovičius ${ }^{2}$, Mantas Vaišnoras ${ }^{3}$ \\ Department of Construction Management and Real Estate, Faculty of Civil Engineering, \\ Vilnius Gediminas Technical University, Vilnius, Lithuania \\ E-mail: ${ }^{1}$ robertas.kontrimovicius@vgtu.lt (corresponding author)
}

\begin{abstract}
Aim of the article: to create a prototype of an information system of an optimized site plan using virtual reality technology (VRT). The article consists of two parts. The first part: the review of the literary sources used; a comparative analysis of the existing models of the construction site plans. Second part: the description of the prototype development of the information system (the algorithm) using building information modeling (BIM), and VRT.
\end{abstract}

Keywords: site plan, building information modelling, virtual reality technologies, photogrammetry.

\section{Introduction}

Applying the building information model is undoubtedly one of the most advanced technologies used in the construction sector, the benefits of which are proven by research. The biggest of the project's problems, especially delays, are due to harmful practices - construction works begin immediately after the contract is signed, without proper analysis of the Client's needs and the existing construction site situation, with no precise planning of resources, supply and production schedules and even budget. During the pre-construction phase, the solutions must be as thoroughly thought and planned as possible, the resources of the workforce and materials, graphs and project estimates must be provided. Mostly analysis of the pre-construction phase is often refused due to: lack of existing situation or design solutions data, complicated calculations of mechanisms, equipment, required storage areas, not enough time to analyse all possible rational solutions.

\section{Literature review}

Technological construction processes are implemented under exceptional, non-recurring conditions in each construction. Construction is characterized by technological processes not used in other industrial sectors. As a result, there are quite large differences between other industries. The main features of the construction sector are:

1. Unique, non-repetitive construction technology;

2. High fragmentation of products, materials used in the building site;

3. Installation of temporary infrastructure;

4. Dependence on seasonality, weather conditions;

5. Different sizes and weights of objects or elements under construction;

6. The long service life of facilities;

7. The unpredictable duration of technological processes.

Based on the key characteristics of the construction industry listed above, we can clearly state that construction management and organization are more complex than other industrial sectors that are predominantly stable and have the potential for process planning.

\section{Construction site design: a literature review}

The area occupied by a construction site (construction site) is considered a scarce resource, unlike building materials, equipment, machinery, labor, time or money (Tommelein \& Zouein, 1993). Properly, efficiently and rationally designed site occupancy will have a positive impact on labor productivity, occupational safety, and site safety, all of 
which will affect project implementation time and project cost. The need for pre-site planning has already been noted by scientists decades ago. Site planning is closely related to other construction management processes such as planning, scheduling, fixed and variable costing (to assess the number of sites needed and the potential site location, the existing site opportunities, and barriers are evaluated). An improperly designed and inefficiently designed site plan results in unexpected additional costs and delays in meeting schedule schedules (El-Rayes \& Khalafallah, 2005).

Given the complexity and a large number of variables, computers have been used for site optimization in 1980 (Sadeghpour, Moselhi, \& Alkass, 2004). Although all the methods used have the same basic purpose, i.e. optimization of the construction site and its layout, however, the literature analysis shows that both the assumptions and the scope are very wide in order to optimize the construction site. The research carried out on-site optimization differs not only in the applied solution search methodology but also in the definition of the site planning problem. Given that there are a large number of variables in site planning, and that existing research differs in the definition of the problem to be solved and the method used to solve it, it may seem that the topic of site optimization is widely analyzed. It is difficult to evaluate and compare different models, their similarities or differences, even though they are trying to solve the same optimization problem.

\section{Modeling of the construction site area}

The ultimate goal of site planning is to rationally position objects related to the construction process on the site (hereinafter referred to as the objects). Therefore, the concept of building site modeling is closely related to the concept of the building site. The formal definition of a site area is important for two reasons: a screening of the size of the site available, and the classification of relevant areas within the site. This section will discuss three methods used in the analyzed literature to describe the modeling of vacant building site areas (zones).

\section{Limited, predefined site area method}

Most models have predefined and defined free zones (areas) on the construction site (Zhang \& Wang, 2008; Mawdesley \& Al-Jibouri, 2003; Zouein, Harmanani, \& Hajar, 2002; Tam, Tong, \& Chan, 2001; Li \& Love, 2000). This assumption simplifies the task of site planning. Therefore, the goal is to distribute $\mathrm{n}$ numbers of objects into relevant, potential $\mathrm{n}$ areas (areas) of the construction site. This simplified approach is also referred to as "space allocation" (Zouein et al., 2002). It is best to use this method when there are very few free zones on the construction site and the free zone is restricted from several sides (Figure 1a). Even more, simplified models assume that projected objects can fit into a defined free area, regardless of the actual dimensions and shapes of the projected objects (Tam et al., 2001; Mawdesley \& Al-Jibouri, 2003; Li \& Love, 2000). In more sophisticated models, free zones tend to have irregular shapes and dimensions. Therefore, object design with irregularly shaped free zones is more complex and more common in real projects (Zhang \& Wang, 2008; Li \& Love, 2000; Zouein et al., 2002). Although a predefined free space suitable for the design of objects simplifies the search for a rational solution, it also reduces the flexibility of possible decisions, as there are clear space constraints. Therefore, the application of this method is limited as it is best applied to construction sites that have a clear restricted area for designing objects, but with several larger available and free areas on the construction sites, the free areas will be divided into zones, in which case will be divided inefficiently, leaving unused areas, so the solution chosen will not always be rational.

\section{Network system method}

Another method used to model a site area is to divide the area using the orthogonal (Cartesian) coordinate system principle, i.e. by dividing into small perpendicular portions of the plane called lattices and forming a whole mesh system. The location of the object is determined by specific coordinates that are non-repetitive (Yahya \& Saka, 2014; Khalafallah \& El-Rayes, 2011; Osman, Georgy, \& Ibrahim, 2003; Cheung, Tong, \& Tam, 2002; Elbeltagi, Hegazy, \& Eldosouky, 2004; Hegazy \& Elbeltagi, 2000). This method facilitates the identification of collisions between the objects being designed. In contrast to the method described above, it is possible to perform an automatic search for objects in a grid system because each object has unique coordinates.

In the simplified model, the individual object is projected in a separate lattice (K. C. Lam, Ning, \& M. C. K. Lam, 2009). In this case, the cell size is directly dependent on the size of the largest object being projected. In a more sophisticated model, an object may not only include one lattice but may be projected across multiple lattices (Elbeltagi \& Hegazy, 2001; Osman et al., 2003; Ning, K. C. Lam, \& M. C. K. Lam, 2010; Khalafallah \& El-Rayes, 2011). Being able to project an object across multiple grids provides a more realistic model - giving you the flexibility to find a rational solution. In addition, it is possible to design objects of various shapes and sizes, as well as to make more effective use of free space.

Thus, the grid system approach allows for a more realistic model than the restricted, predefined site area method. However, the grid system method has two limitations: the shape of the object being projected is limited to perpendicular lines, whereas the grid system is divided into perpendicular lattices, and. For example, the location B 'of the object in 
Figure $1 \mathrm{~b}$ will never be selected as rational, even if location $\mathrm{B} 1$ is more rational than location $\mathrm{B}$. The solution to this problem may be to divide the mesh system into smaller cells. However, this will significantly increase the number of cells and not only lengthen the computation but also make it more complex.

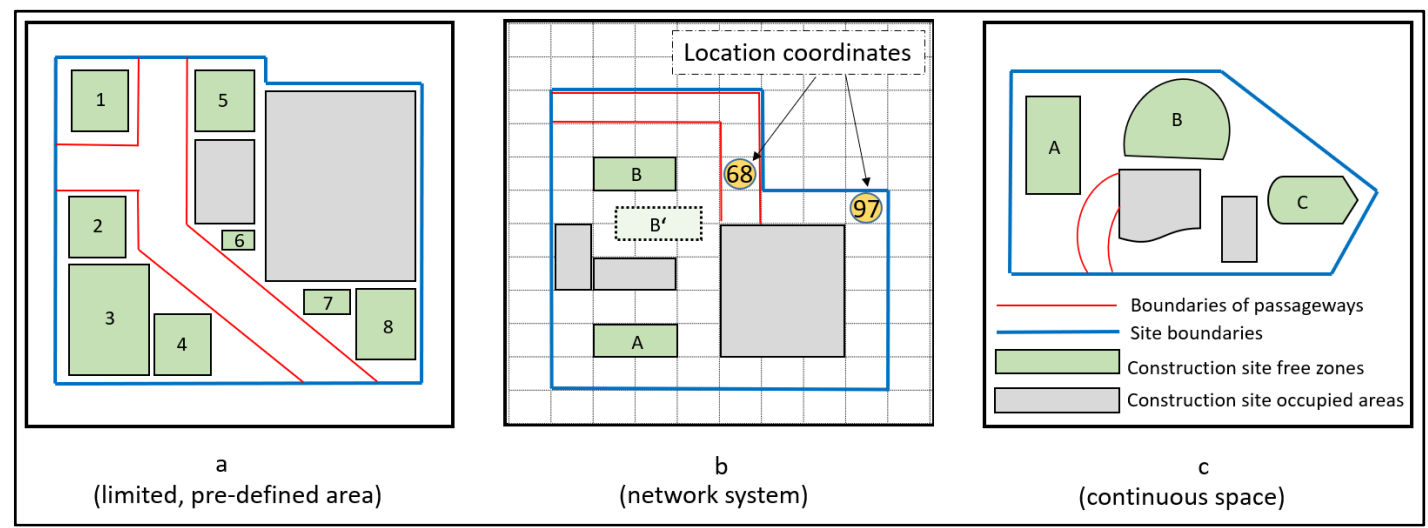

Figure 1. Geometry of object boundaries (author created)

\section{Continuous space method}

It is clear that, in reality, the design site for objects is not limited to the mesh partitioning of the construction site. Using the continuous space method, space is formed as a continuous quantum (Figure 1c) (Andayesh \& Sadeghpour, 2011; Easa \& Hossain, 2008; Sadeghpour, Moselhi, \& Alkass, 2006; Zouein et al., 2002). This method allows the object to be projected anywhere in the open space, not limited to grid-specific grids or restricted, predefined locations. However, in comparison to the previously explored methods, the continuous space method requires sophisticated computational algorithms to avoid collisions and find a rational solution.

\section{Object boundaries}

It is also important to define boundaries (dimensions and shape) of the site in order to identify the required space on the site and to avoid collisions between individual sites. This section will discuss three methods that are commonly used to show the specific boundaries of an object.

\section{An object without dimensions (dimensionless)}

This method assigns points that have neither dimension nor shape (Mawdesley \& Al-Jibouri, 2003; Tam et al., 2001). Such a point definition of an object is sufficient to solve the problem of space distribution. However, when looking for a rational solution, the dimensions, and shape of the object are not taken into account, so there is no need to check for collisions. This method cannot be used in confined, predefined areas on the construction site.

\section{Approximate object geometry}

The real irregular shape of the object is simplified and is close to the regular shape, i.e. rectangle or sphere, this assumption is often used in previous research (Andayesh \& Sadeghpour, 2011; Khalafallah \& El-Rayes, 2011; Ning et al., 2010; Easa \& Hossain, 2008; El-Rayes \& Said, 2009; Hammad, Zhang, Al-Hussein, \& Cardinal, 2007; Zouein et al., 2002). Replacing an object of a real irregular shape with the nearest object of regular shape gives a more realistic result than the method of changing an object to a point. In addition, the approximate geometry method makes it possible to make more efficient use of the construction site's free space. Accepting correctly shaped objects in calculations facilitates collision detection and calculations faster than calculating objects with irregularly shaped objects. However, in areas with dense built-up, changing the shape of an object to a regular shape can often be ineffective, since the theoretical area occupied by a regular object will be larger than the area actually occupied.

\section{Actual (real) shape of the object}

This method is applicable to objects whose shape and dimensions are accurate and fully correspond to reality. Although calculations become more complex, accurate representation of object dimensions and shapes is important in dense and complex buildings, such as in a city center where both buildings are of irregular shape, dimensions and buildings are close to each other and there is little free space. Using the grid system method, the actual shape of an object will span 

and temporary objects, using virtual reality technology

multiple cells adjacent to it. Sophisticated algorithms and computational methods are used to model the actual-form object by the continuous-space method (Sadeghpour et al., 2006). Figure 2 provides a graphical illustration showing possible combinations of different building site areas and site boundaries.

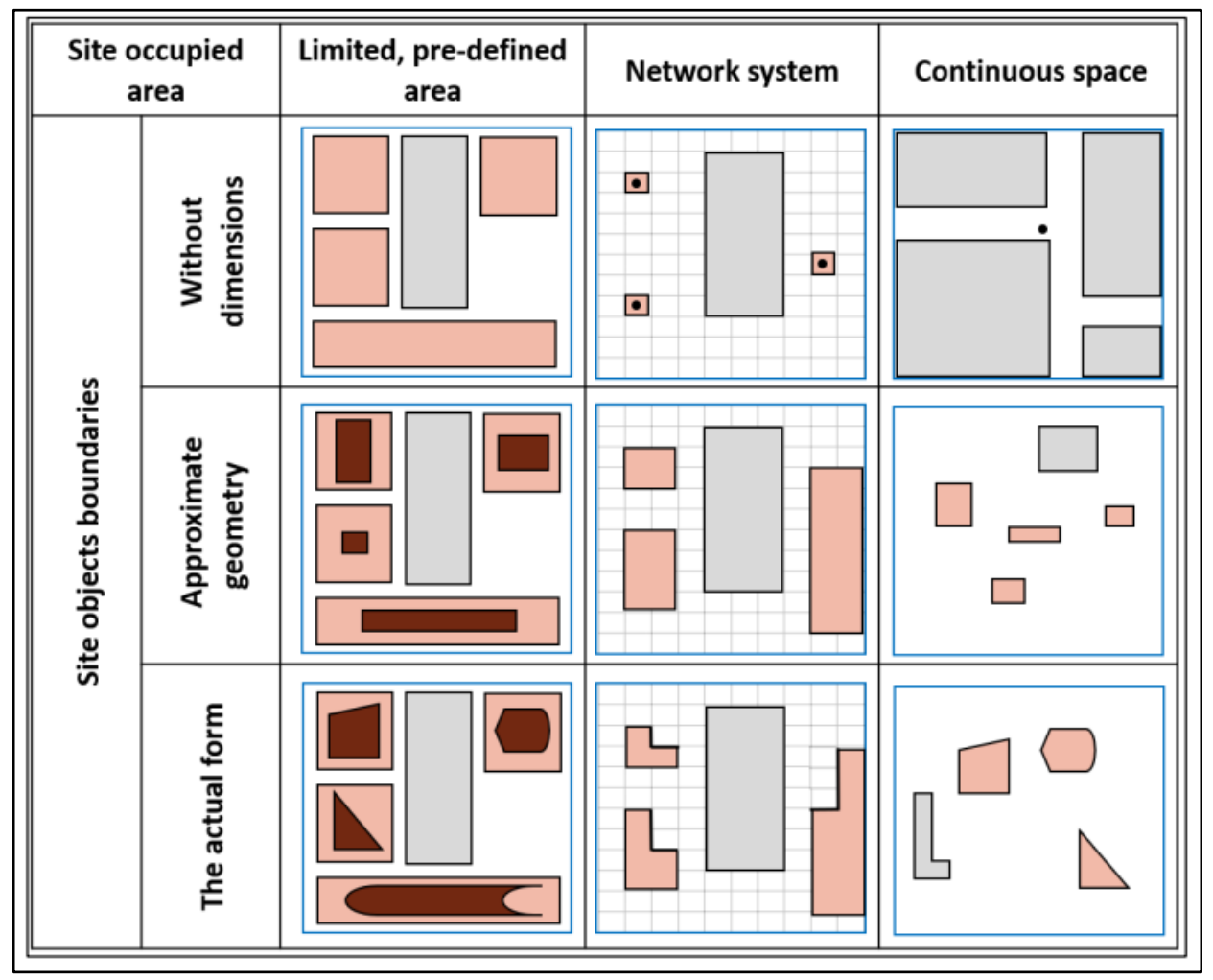

Figure 2. Possible construction site area and objects outside the combinations (author created)

\section{Development of information system prototype}

Construction site design can be divided into several stages. The first phase consists of a fixed part of the construction site which cannot be changed during the entire construction period. There is only one option available at this stage. This phase includes the existing plot of land where the construction work is planned.

Taking into account the existing scientific literature and the capabilities of the existing software, this section will describe the development of a prototype of an optimized site plan information system using virtual reality technology (hereinafter referred to as the platform).

\section{The first step is to identify the current situation}

The image reconstruction algorithm of the building (under construction, projected, existing) is shown in Figure 3. First of all, the database of the group of buildings under construction (planned, existing, demolished) retrieves the data of the required buildings to be drawn and their layout from the virtual reality model (step 1). The data from the individual object database is then read (step 2). The process of scraping each individual contour element depends on whether it is a straight element or a circular curve. If it is a straight element, it is drawn to a point whose coordinates are given in the section of the database, but if it is an element of a circular curve, the drawing of this element is formalized and related calculations are performed.

\section{Selection of site planning method}

The analysis of the current state aims to determine the method of planning the vacant site area. As mentioned in the analysis, three construction site design methods are distinguished - continuous space, grid system, and finite, predefined area. In order to proceed with further calculations, it is necessary to choose the appropriate method, taking into account the available baseline data, the quality of the desired result and the time of execution. Figure 4 shows the algorithm of the platform operating principle. 
Kontrimovičius, R.; Ustinovičius, L.; Vaišnoras, M. 2019. Calculating and estimating construction site plan preparation works and temporary objects, using virtual reality technology

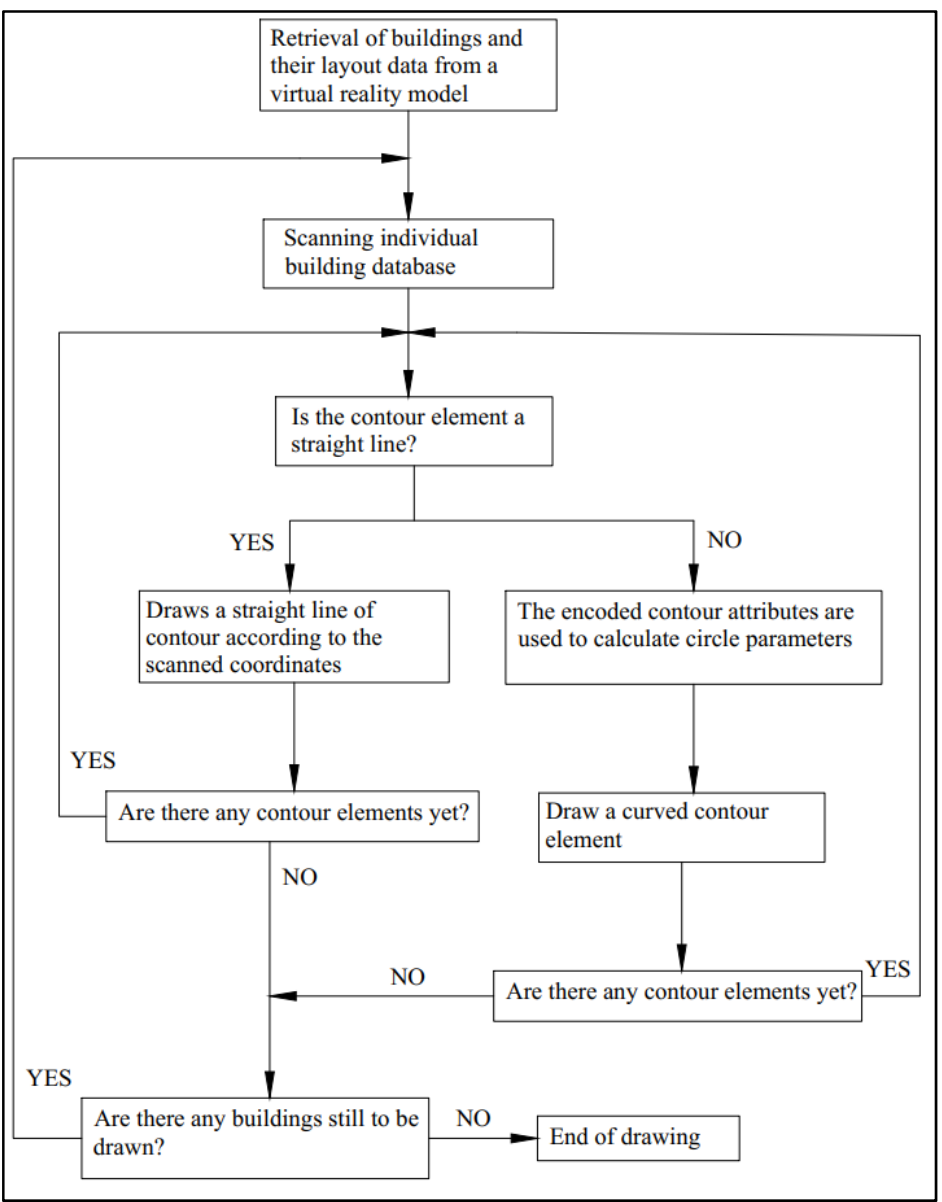

Figure 3. Object contour drawing recovery algorithm (author created)

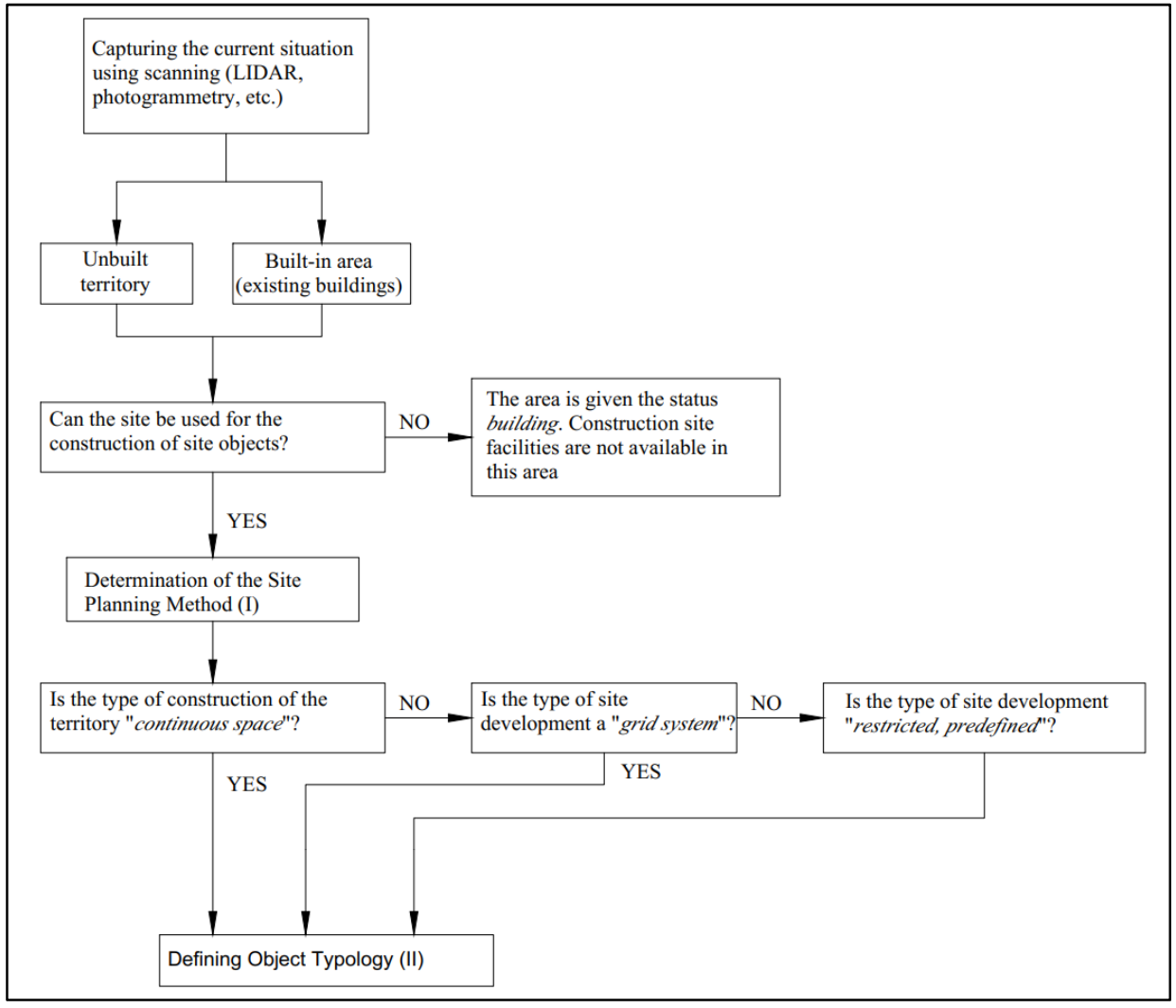

Figure 4. Prototype for site area identification (author created) 


\section{Defining object typology}

Selecting the type of site development further determines the object's typology. The object typology is determined in a linear fashion to perform a calculation of the quantities needed for each possible object (Figure 5). Once the need for the facility is identified, the actual boundaries (dimensions, height) of the facility are determined to identify at a later stage whether the facility will be available on the construction site.

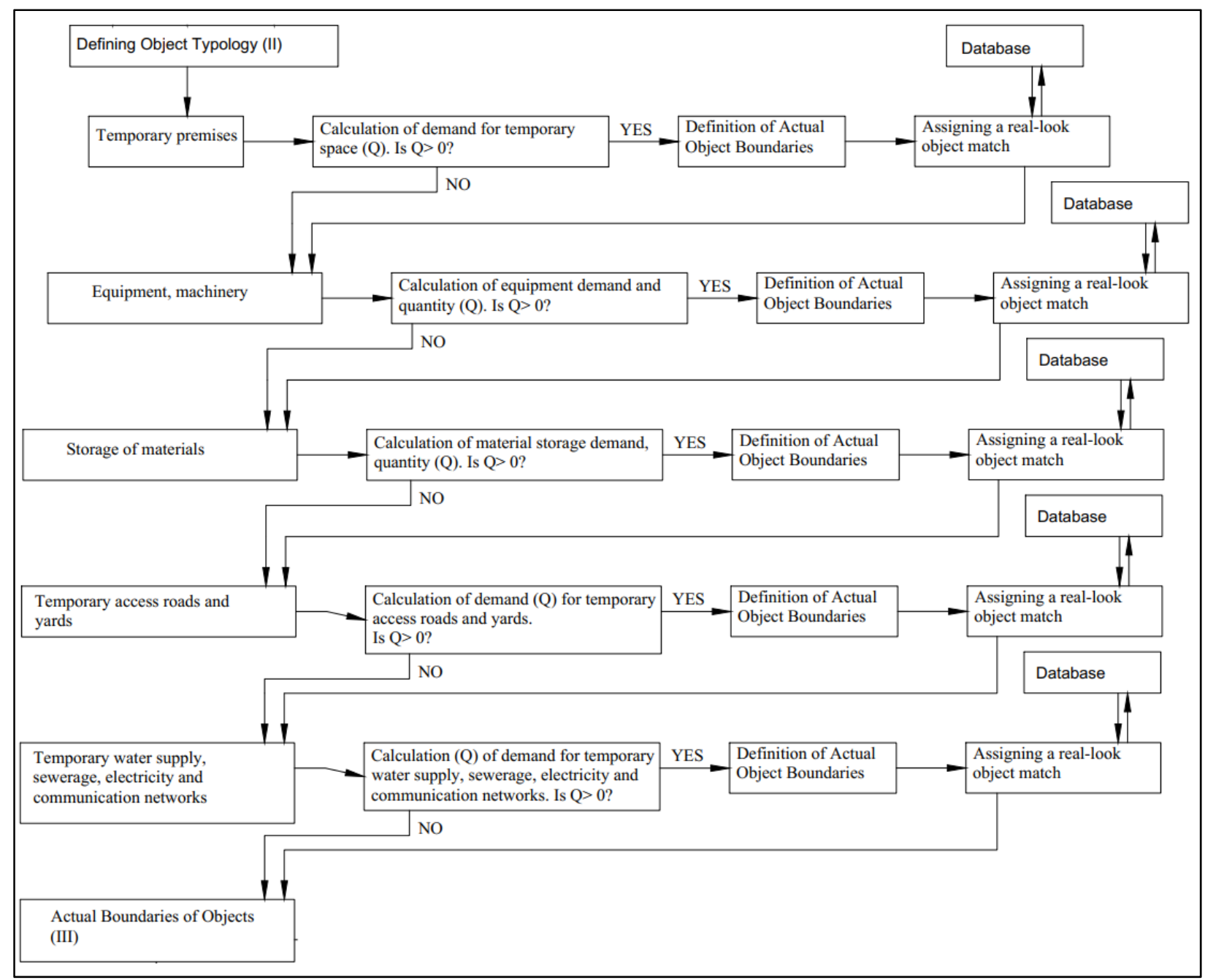

Figure 5. Prototype for setting object typology (author created)

Further utilizing the capabilities of virtual reality, an object of realistic appearance and shape is selected based on the actual object boundaries provided, using a library, directory created in the database. The calculation and identification of the needs of other objects are continued. The main objects of the construction site are temporary premises, equipment, machinery, material storage, and unloading sites, temporary access roads and sites, temporary water supply, sewerage, electricity and communication networks.

\section{Application of the object bounding method}

In order to make effective use of the entire vacant site area, it is necessary to identify the actual boundaries of existing structures. For this purpose, a photogrammetric model is used, converting the point cloud to a digital object (solid).

Depending on the possible boundary demarcation methods, one of the possible ones shall be selected in the construction of a site-wide planning model. By choosing the actual object boundary method, the boundaries of buildings and existing or planned objects are rendered, retaining all real dimensions and shapes (Figure 6), and simplifying the visualization of the object by converting it to a digital form object (solid). The simplified rendering leaves all the real shapes and dimensions but replaces the real visual with the typical digital form of the design environment (solid).

When the Approximate Geometry method is selected, a geometric object of regular shape is selected with respect to real dimensions and shape, provided that the real dimensions are not larger than the geometric object of regular shape. The method chosen saves the time needed to calculate the site plan. 
Kontrimovičius, R.; Ustinovičius, L.; Vaišnoras, M. 2019. Calculating and estimating construction site plan preparation works and temporary objects, using virtual reality technology

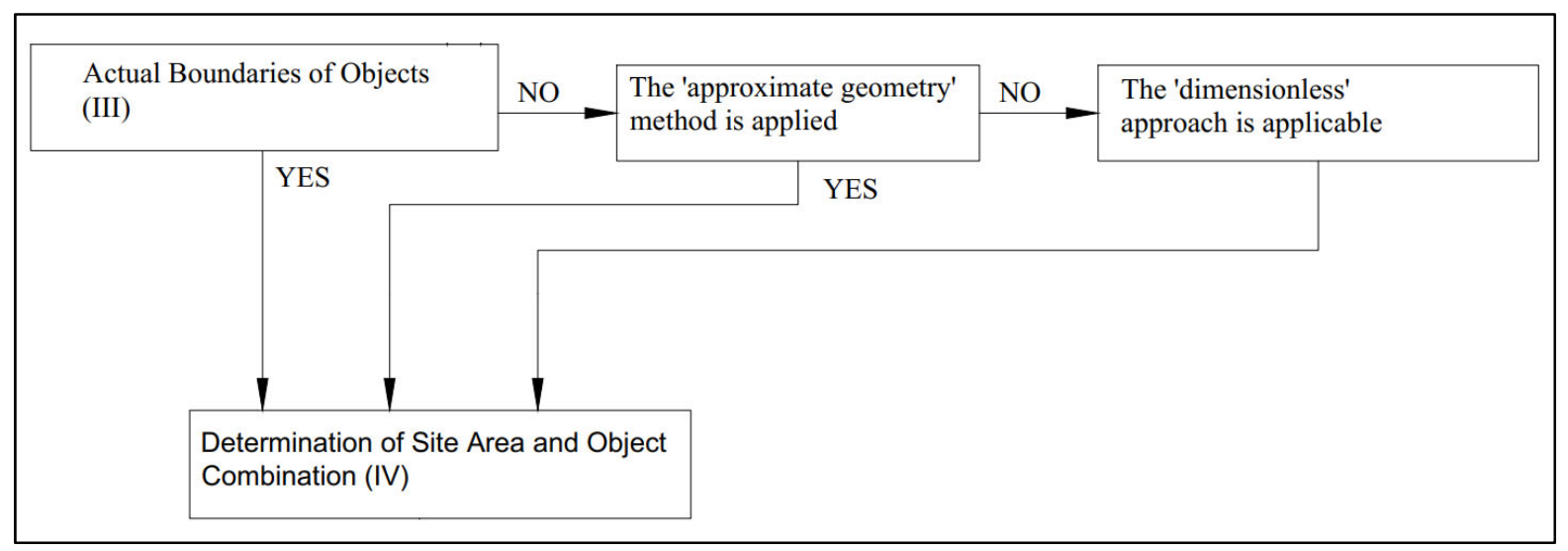

Figure 6. Object boundary prototype (author created)

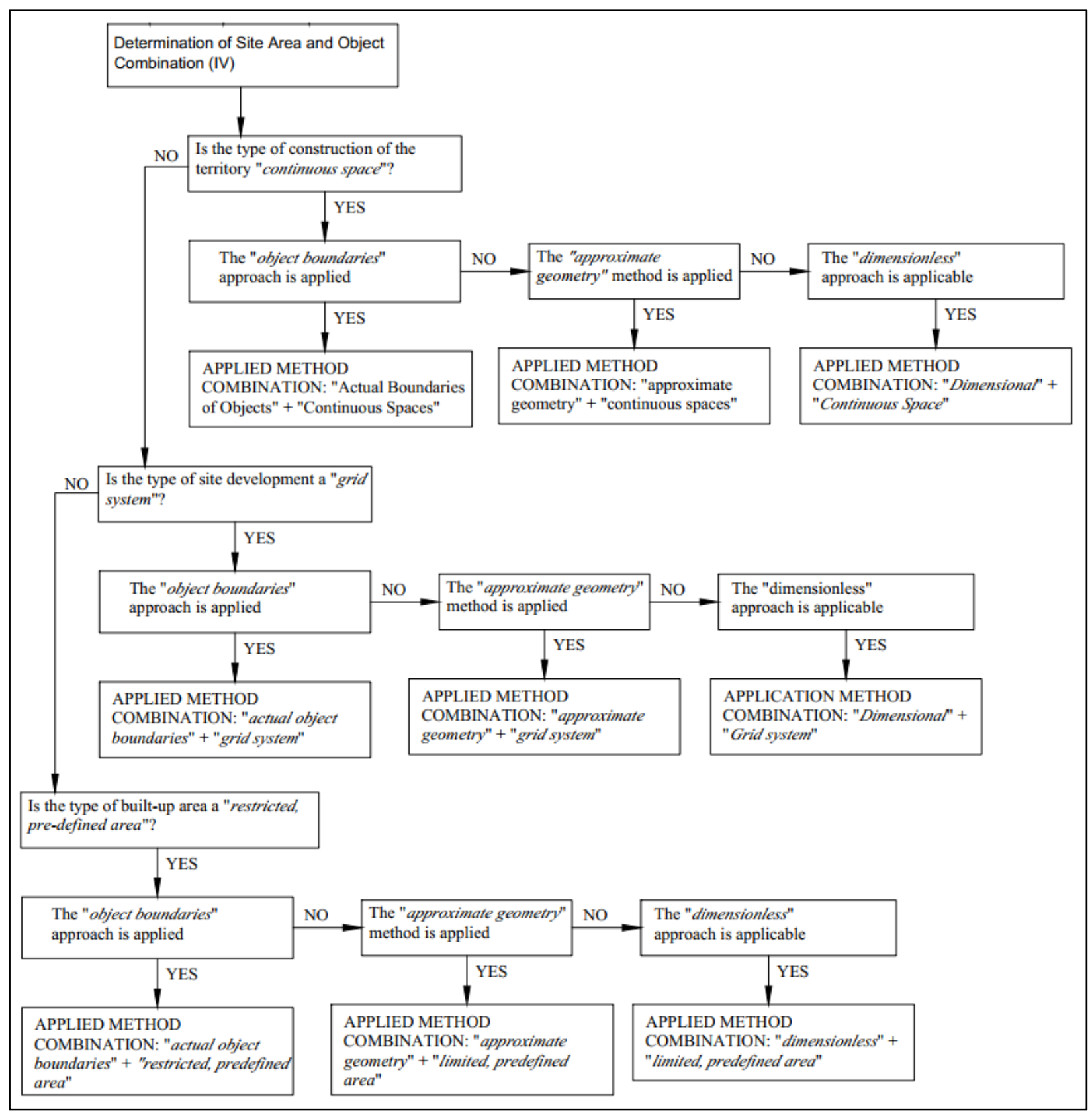

Figure 7. Prototype for site alignment and object alignment (author created) 
The simplest site planning method is the point method or "dimensionless". This means that no matter the size or shape of the object, it is represented by a single point in the plan, at the geometric center.

Using this point method, it is not known exactly how much space the site occupies in the site plan. Therefore, the use of the site area in this method is inefficient and often collides with adjacent objects. This method is applicable when the dimensions of real objects are unknown or difficult to predict. For example, a pile of gravel or sand is used for construction purposes. Only the preliminary dimensions can be predicted, so the point method is appropriate in this case.

\section{Determination of site area and combination of objects}

After determining the type of the building and the method used for the boundaries of the site, the site area and the combination of objects are determined. The criteria listed in Figure 7 identify the specific combination of site plan modeling to be used. The choice of the appropriate combination depends on the precise use of the data. It is not expedient to use the most complex combinations in all cases, as not only does it take more time, but the calculations themselves become more complex, which makes the computation errors more likely.

\section{Conclusions}

The extensive literature analysis has shown that due to a large number of variables that are associated with the construction site model, the assumptions and capabilities are significantly different, but that common research aspect is identified in the methods being analysed that define a general plan for site design. This general plan is used to develop new construction site models in this research work. Software analysis has shown that there is no single software that combines and enables automated selection of all site-based machinery and equipment on a single platform. Developed plugins allow you to create software code that performs automated mechanism selection, optimization of selected mechanisms, but these plugins are not properly integrated into all design and construction organization software. The principle of mathematical model formation of the site object needs was formed and the methodology and classification of the main site objects were developed. An optimized site plan algorithm was developed. The research work was found to be continuous, as the optimized site plan information system prototype developed is generic and is intended for the main stage of construction work, i.e. for the ground installation phase. In order to optimize and automate modeling of site planning, selection of machinery, equipment, and other temporary objects, it is necessary to integrate into the existing information system prototype and other stages of construction work - earthworks, zero-cycle construction, engineering networks and communications, environmental management, etc. Also to complete the classification system created by machinery, equipment, and temporary objects.

\section{References}

Andayesh, M., \& Sadeghpour, F. (2011). Dynamic site layout planning using MTPE principle from physics. In Proceedings of the $28^{\text {th }}$ Annual Conference of International Symposium on Automation and Robotics in Construction. Seoul, Korea. https://doi.org/10.22260/ISARC2011/0159

Cheung, S. O., Tong, T. K. L., \& Tam, C. M. (2002). Site pre-cast yard layout arrangement through genetic algorithms. Automation in Construction, 11(1), 35-46. https://doi.org/10.1016/S0926-5805(01)00044-9

Easa, S. M., \& Hossain, K. M. A. (2008). New mathematical optimization model for construction site layout. Journal of Construction Engineering and Management, 134(8), 653-662. https://doi.org/10.1061/(ASCE)0733-9364(2008)134:8(653)

Elbeltagi, E., \& Hegazy, T. (2001). A hybrid AI-based system for site layout planning in construction. Computer-Aided Civil and Infrastructure Engineering, 16(2), 79-93. https://doi.org/10.1111/0885-9507.00215

Elbeltagi, E., Hegazy, T., \& Eldosouky, A. (2004). Dynamic layout of construction temporary facilities considering safety. Journal of Construction Engineering and Management, 130(4), 534-541. https://doi.org/10.1061/(ASCE)0733-9364(2004)130:4(534)

El-Rayes, K., \& Khalafallah, A. (2005). Trade-off between safety and cost in planning construction site layouts. Journal of Construction Engineering and Management, 131(11), 1186-1195. https://doi.org/10.1061/(ASCE)0733-9364(2005)131:11(1186)

El-Rayes, K., \& Said, H. (2009). Dynamic site layout planning using approximate dynamic programming. Journal of Computing in Civil Engineering, 23(2), 119-127. https://doi.org/10.1061/(ASCE)0887-3801(2009)23:2(119)

Hammad, A., Zhang, C., Al-Hussein, M., \& Cardinal, G. (2007). Equipment workspace analysis in infrastructure projects. Canadian Journal of Civil Engineering, 34(10), 1247-1256. https://doi.org/10.1139/107-048

Hegazy, T., \& Elbeltagi, E. (2000). Simplified spreadsheet solution: a model for site layout planning. Cost Engineering, 42(1), 2430.

Khalafallah, A., \& El-Rayes, K. (2011). Automated multi-objective optimization system for airport site layouts. Automation in Construction, 20(4), 313-320. https://doi.org/10.1016/j.autcon.2010.11.001

Lam, K. C., Ning, X., \& Lam, M. C. K. (2009). Conjoining MMAS to GA to solve construction site layout planning problem. Journal of Construction Engineering and Management, 135(10), 1049-1057. https://doi.org/10.1061/(ASCE)0733-9364(2009)135:10(1049) 
Kontrimovičius, R.; Ustinovičius, L.; Vaišnoras, M. 2019. Calculating and estimating construction site plan preparation works and temporary objects, using virtual reality technology

Li, H., \& Love, P. E. D. (2000). Genetic search for solving construction site-level unequal-area facility layout problems. Automation in Construction, 9(2), 217-226. https://doi.org/10.1016/S0926-5805(99)00006-0

Mawdesley, M. J., \& Al-Jibouri, S. H. (2003). Proposed genetic algorithms for construction site layout. Engineering Applications of Artificial Intelligence, 16(5-6), 501-509. https://doi.org/10.1016/j.engappai.2003.09.002

Ning, X., Lam, K. C., \& Lam, M. C. K. (2010). Dynamic construction site layout planning using max-min ant system. Automation in Construction, 19(1), 55-65. https://doi.org/10.1016/j.autcon.2009.09.002

Osman, H. M., Georgy, M. E., \& Ibrahim, M. E. (2003). A hybrid cad-based construction site layout planning system using genetic algorithms. Automation in Construction, 12(6), 749-764. https://doi.org/10.1016/S0926-5805(03)00058-X

Sadeghpour, F., Moselhi, O., \& Alkass, S. (2004). A CAD-based model for site planning. Automation in Construction, 13(6), 701715. https://doi.org/10.1016/j.autcon.2004.02.004

Sadeghpour, F., Moselhi, O., \& Alkass, S. T. (2006). Computer-aided site layout planning. Journal of Construction Engineering and Management, 132(2), 143-151. https://doi.org/10.1061/(ASCE)0733-9364(2006)132:2(143)

Tam, C. M., Tong, T. K., \& Chan, W. K. W. (2001). Genetic algorithm for optimizing supply locations around tower crane. Journal of Construction Engineering and Management, 127(4), 315-321. https://doi.org/10.1061/(ASCE)0733-9364(2001)127:4(315)

Tommelein, I. D., \& Zouein, P. P. (1993). Interactive dynamic layout planning. Journal of Construction Engineering and Management, 119(2), 266-287. https://doi.org/10.1061/(ASCE)0733-9364(1993)119:2(266)

Yahya, M., \& Saka, M. P. (2014). Construction site layout planning using multi-objective artificial bee colony algorithm with Levy flights. Automation in Construction, 38, 14-29. https://doi.org/10.1016/j.autcon.2013.11.001

Zhang, H., \& Wang, J. Y. (2008). Particle swarm optimization for construction site unequal-area layout. Journal of Construction Engineering and Management, 134(9), 739-748. https://doi.org/10.1061/(ASCE)0733-9364(2008)134:9(739)

Zouein, P. P., Harmanani, H., \& Hajar, A. (2002). Genetic algorithm for solving site layout problem with unequal-size and constrained facilities. Journal of Computing in Civil Engineering, 16(2), 143-151. https://doi.org/10.1061/(ASCE)0887-3801(2002)16:2(143) 